\title{
The status of the species Lactobacillus casei (Orla-Jensen 1916) Hansen and Lessel 1971 and Lactobacillus paracasei Collins et al. 1989. Request for an Opinion
}

Dipartimento Scientifico e Tecnologico, Facoltà di Scienze MM. FF. NN., Università degli Studi di Verona, Strada le Grazie 15, 37134 Verona $^{1}$ and DOFATA, Università degli Studi di Catania, 95124 Catania², Italy

\author{
Franco Dellaglio, ${ }^{1}$ Giovanna E. Felis ${ }^{1}$ and Sandra Torriani ${ }^{1,2}$ \\ Author for correspondence: Franco Dellaglio. Tel: +39 45 8027917. Fax: + 39458027928. \\ e-mail: dellaglio@sci.univr.it
}

\begin{abstract}
On the basis of considerable published evidence, it is concluded that the species Lactobacillus casei is not correctly represented by the strain actually designated as the type strain ATCC 393. It is proposed that the Judicial Commission consider: (1) that ATCC $393^{\top}$ is scientifically unsuitable as the type strain of Lactobacillus casei and should be reclassified as Lactobacillus zeae; (2) that Lactobacillus casei ATCC 334 and Lactobacillus paracasei strains are members of the same taxon and therefore can be united within the name Lactobacillus casei (Rules 42 and 23a), the name Lactobacillus paracasei being rejected; and (3) designating ATCC 334 as the neotype strain for the species Lactobacillus casei.
\end{abstract}

Keywords: Lactobacillus casei, Lactobacillus paracasei, Request for an Opinion, Bacteriological Code
A previous Request for an Opinion on the nomenclature of the Lactobacillus casei species group (Dellaglio et al., 1991) was rejected by the Judicial Commission because '... there is not enough basis for concern about confusion leading to serious consequences in industrial microbiology to justify awarding an exception to the Rules' (Wayne, 1994). However, in recent years we have assisted with a series of publications dealing with new Lactobacillus species in which the reference strain or, in some cases the type strain, of the species Lactobacillus casei was alternatively ATCC 334 (Yoon et al., 2000; Cai et al., 1999; Morlon-Guyot et al., 1998) or ATCC 393 (Edwards et al., 2000; Kato et al., 2000; Swezey et al., 2000; Tanasupawat et al., 2000). Moreover, either ATCC 393 (= LMG 6904) (Morlon-Guyot et al., 1998) or LMG 17315 (= ATCC 15820) (Cai et al., 1999) has been used as the type strain for the species Lactobacillus zeae.

The precise individuation of a type strain for analysis has importance from both scientific and industrial points of view. In fact, taxonomic and phylogenetic relationships between species are often delineated entirely on the basis of the type strains, which therefore have to be representative. This also has practical implications, as these Lactobacillus species are often isolated from foods and are largely employed in the food industry.
A chronological summary of the scientific evidence concerning the 25-year-old taxonomic problem of Lactobacillus casei is reported here for ease of comprehension.

(1) The emended description of Lactobacillus casei (Orla-Jensen 1916) comb. nov. by Hansen \& Lessel (1971) was based on the neotype strain ATCC 393. No original strains representing Lactobacillus casei in live form were available other than strain ATCC 393, which was believed to be a subculture of strain no. 7 from the Orla-Jensen strain collection, and it was believed that it represented a typical Lactobacillus casei. However, this assumption was made on the basis of phenotypic traits only.

(2) DNA-DNA hybridization experiments performed in two independent studies (Mills \& Lessel, 1973; Dellaglio et al., 1975) showed that Lactobacillus casei subsp. casei ATCC $393^{\mathrm{T}}$ was genotypically strongly related to Lactobacillus casei subsp. rhamnosus ATCC 15820, the former type strain of 'Lactobacterium zeae' (Kuznetsov, 1959). Moreover, it was not related to any of the other strains within the subspecies of Lactobacillus casei (homology values were between 43 and $50 \%$ ). Therefore, shortly after its designation, strain ATCC $393^{\mathrm{T}}$ was shown to be unsuitable as the neotype strain of Lactobacillus casei species. 
(3) The true status of 'Lactobacterium zeae' (actually Lactobacillus zeae; Dicks et al., 1996) was overlooked and, accordingly, neglected during the preparation of the Approved List of Bacterial Names in 1980.

(4) DNA homology studies performed by Collins et al. (1989) revealed that the majority of strains designated as Lactobacillus casei (divided into different subspecies) exhibited high levels of DNA relatedness with each other $(61-100 \%)$ but were unrelated $(10-20 \%)$ to Lactobacillus casei subsp. casei ATCC $393^{\mathrm{T}}$. In the light of those experiments, these workers proposed to create the species Lactobacillus paracasei for strains unrelated to Lactobacillus casei ATCC $393^{\mathrm{T}}$. However, Collins et al. omitted to test the relatedness between ATCC $393^{\mathrm{T}}$ and Lactobacillus casei subsp. rhamnosus ATCC 15820.

(5) Numerical analysis of total soluble cell protein and DNA-DNA hybridization experiments performed by Dellaglio et al. (1991) corresponded to the results of Dellaglio et al. (1975) and Collins et al. (1989), but the request for ATCC 334 to be designated, in place of ATCC 393, as the neotype strain of L. casei (together with the rejection of the name Lactobacillus paracasei) was denied (Wayne, 1994).

(6) The randomly amplified polymorphic DNA PCR fingerprints obtained by Dicks et al. (1996) strongly confirmed the results obtained previously (Dellaglio et al., 1975, 1991; Collins et al., 1989). In this paper, the species Lactobacillus zeae was validly proposed but this epithet referred only to strain ATCC 15820.

(7) A comparative sequence analysis of the genes encoding 16S rRNA of Lactobacillus casei-related taxa has recently shown that Lactobacillus casei ATCC 334 and other strains of the species Lactobacillus paracasei had the same 16S rDNA sequences. In contrast, ATCC $393^{\mathrm{T}}$ had its own sequence, which differs from that of Lactobacillus zeae ATCC $15820^{\mathrm{T}}$ and from that of the Lactobacillus casei ATCC 334/Lactobacillus paracasei group. Moreover, the difference between ATCC $393^{\mathrm{T}}$ and the Lactobacillus casei ATCC 334/Lactobacillus paracasei group is greater (twofold) than that between ATCC $393^{\mathrm{T}}$ and Lactobacillus zeae (Mori et al., 1997). Their findings support the request for the taxonomic position of the Lactobacillus casei group proposed by Dellaglio et al. (1991).

(8) An RFLP analysis and a chromotyping analysis performed on type, reference, clinical, health-food and stock isolates of Lactobacillus species with $B c l$ I and DraI revealed a different pattern for Lactobacillus casei ATCC 393 and Lactobacillus casei ATCC 334. In contrast, ATCC 334 and the Lactobacillus paracasei strains (Zhong et al., 1998) shared a similar profile.

(9) In 1999, Tynkkynen et al. demonstrated that the exact identification of Lactobacillus casei group strains by phenotypic traits was not reliable at the species level. Moreover, randomly amplified polymorphic DNA PCRs, ribotyping, PFGEs, and species-specific PCRs produced results in accordance with the classifi- cation of the Lactobacillus casei group suggested by Dellaglio et al. (1991) and Dicks et al. (1996).

(10) A further analysis of the genes encoding 23S-5S rRNA intergenic spacer regions, together with an rRNA RFLP, showed that Lactobacillus casei ATCC $393^{\mathrm{T}}$ has spacers 197 and $117 \mathrm{bp}$ in length while those of the Lactobacillus casei-related strains are 198 and $122 \mathrm{bp}$ long. Moreover, the sequence of the long intergenic spacer region of strain ATCC $393^{\mathrm{T}}$ has only about $80 \cdot 2 \%$ similarity with the spacers of the other strains of Lactobacillus paracasei and $72.4 \%$ for the short intergenic spacer region. Finally, the BamHI and Pst I ribotypes of strain ATCC $393^{\mathrm{T}}$ were distinct from the others in the group, whereas strain ATCC 334 shared high levels of similarity with them (Chen et al., 2000). Their results support the request for the taxonomic position of the Lactobacillus casei group proposed by Dellaglio et al. (1991).

(11) A comparative analysis performed on partial sequences of the rec $A$ gene strongly support the view that ATCC 393 and Lactobacillus zeae ATCC $15820^{\mathrm{T}}$ share a great degree of similarity but are clearly distinct from Lactobacillus casei ATCC 334 and Lactobacillus paracasei strains. Moreover, ATCC 334 and the Lactobacillus paracasei group are genetically very closely related and belong to the same taxon (Felis et al., 2001).

On the basis of the data reported, we conclude that ATCC 393 is not, and never has been, a typical Lactobacillus casei strain. We are referring this matter to the Judicial Commission (Rule $18 \mathrm{~g}$ of the Bacteriological Code; Lapage et al., 1992) and propose that the Judicial Commission consider the following course of action.

(1) Strain ATCC 393, as the neotype of the species Lactobacillus casei (Orla-Jensen 1916) Hansen and Lessel 1971, should be recognized as scientifically unsuitable (Rule 18g) since it does not genetically represent the species Lactobacillus casei. Furthermore, recent genotypic evidence (Mori et al., 1997; Tynkkynen et al., 1999; Chen et al., 2000; Felis et al., 2001) strongly supports previous indications (Mills \& Lessel, 1973; Dellaglio et al., 1975, 1991; Dicks et al., 1996) that strains ATCC 393 and ATCC 15820 are members of the same taxon. Even though the valid status of the species Lactobacillus zeae was recognized only in 1996 (Dicks et al., 1996), the misidentified strain ATCC 393 is closely related to the type strain of this species. We ask the Judicial Commission to pronounce on the classification of strain ATCC 393. On the basis of the evidence reported, we propose that it could be allotted to the species Lactobacillus zeae (ex 'Lactobacterium zeae' Kuznetsov 1959) (Dicks et al., 1996).

(2) The strains of the Lactobacillus casei and Lactobacillus paracasei species form a single taxon, and therefore we ask the Judicial Commission to unite them in a single species with the name Lactobacillus 
casei, the oldest legitimate name (Rules 42 and 23a), and to reject the name Lactobacillus paracasei (Collins et al., 1989). We also ask the Judicial Commission to maintain the previous subspecies of Lactobacillus casei, i.e. Lactobacillus casei subsp. casei and Lactobacillus casei subsp. tolerans.

(3) On the basis that the species Lactobacillus casei has no type strain (see Request 1), we propose strain ATCC 334 as the neotype, since it has been already proposed (Dellaglio et al., 1991; Dicks et al., 1996), supported (Mori et al., 1997; Tynkkynen et al., 1999; Chen et al., 2000; Felis et al., 2001) and used as a reference strain (Yoon et al., 2000; Cai et al., 1999; Morlon-Guyot et al., 1998) (Rule 19). Furthermore, strain LMG $9191^{\mathrm{T}}$ may be retrieved as the type strain of the subspecies Lactobacillus casei subsp. tolerans.

\section{REFERENCES}

Cai, Y., Okada, H., Mori, H., Benno, Y. \& Nakase, T. (1999). Lactobacillus paralimentarius sp. nov., isolated from sourdough. Int J Syst Bacteriol 49, 1451-1455.

Chen, H., Lim, C. K., Lee, Y. K. \& Chan, Y. N. (2000). Comparative analysis of the genes encoding 23S-5S rRNA intergenic spacer regions of Lactobacillus casei-related strains. Int J Syst Evol Microbiol 50, 471-478.

Collins, M. D., Phillips, B. A. \& Zanoni, P. (1989). Deoxyribonucleic acid homology studies of Lactobacillus casei, Lactobacillus paracasei $\mathrm{sp}$. nov., subsp. paracasei and subsp. tolerans, and Lactobacillus rhamnosus sp. nov., comb. nov. Int J Syst Bacteriol 39, 105-108.

Dellaglio, F., Bottazzi, V. \& Vescovo, M. (1975). Deoxyribonucleic acid homology among Lactobacillus species of the subgenus Streptobacterium Orla-Jensen. Int J Syst Bacteriol 25, 160-172.

Dellaglio, F., Dicks, L. M. T., Du Toit, M. \& Torriani, S. (1991). Designation of ATCC 334 in place of ATCC 393 (NCDO 161) as the neotype strain of Lactobacillus casei subsp. casei, and rejection of the name Lactobacillus paracasei (Collins et al., 1989). Request for an Opinion. Int J Syst Bacteriol 41, 340-342.

Dicks, L. M. T., Du Plessis, E. M., Dellaglio, F. \& Lauer, F. (1996). Reclassification of Lactobacillus casei subsp. casei ATCC 393 and Lactobacillus rhamnosus ATCC 15820 as Lactobacillus zeae nom. rev., designation of ATCC 334 as the neotype of L. casei, and rejection of the name Lactobacillus paracasei. Int $J$ Syst Bacteriol 46, 337-340.

Edwards, C. G., Collins, M. D., Lawson, P. A. \& Rodriguez, A. V. (2000). Lactobacillus nagelii sp. nov., an organism isolated from a partially fermented wine. Int J Syst Evol Microbiol 50, 699-702.

Felis, G. E., Dellaglio, F., Mizzi, L. \& Torriani, S. (2001). Com- parative sequence analysis of a $\operatorname{rec} A$ gene fragment brings new evidence for a renewal in the taxonomy of the Lactobacillus casei group. Int J Syst Evol Microbiol 51, 2113-2117.

Hansen, P. A. \& Lessel, E. F. (1971). Lactobacillus casei (OrlaJensen) comb. nov. Int J Syst Bacteriol 21, 69-71.

Kato, Y., Sakala, R. M., Hayashidani, H., Kiuchi, A., Kaneuchi, C. \& Ogawa, M. (2000). Lactobacillus algidus sp. nov., a psychrophilic lactic acid bacterium isolated from vacuum-packaged refrigerated beef. Int J Syst Evol Microbiol 50, 1143-1149.

Kuznetsov, V. D. (1959). A new species of lactic acid bacteria. Mikrobiologiya 28, 248-351.

Lapage, S. P., Sneath, P. H. A., Lessel, E. F., Skerman, V. B. D., Seeliger, H. P. R. \& Clark, W. A. (editors) (1992). International Code of Nomenclature of Bacteria (1990 Revision). Bacteriological Code. Washington, DC: American Society for Microbiology.

Mills, C. K. \& Lessel, E. F. (1973). Lactobacterium zeae Kuznetsov, a later subjective synonym of Lactobacillus casei (Orla-Jensen) Hansen and Lessel. Int J Syst Bacteriol 23, 430-432.

Mori, K., Yamazaki, K., Ishiyama, T., Katsumata, M., Kobayashi, K., Kawai, Y., Inoue, N. \& Shinano, H. (1997). Comparative sequence analysis of the genes coding for 16S rRNA of Lactobacillus casei-related taxa. Int J Syst Bacteriol 47, 54-57.

Morlon-Guyot, J., Guyot, J. P., Pot, B., Jacobe de Haut, I. \& Raimbault, M. (1998). Lactobacillus manihotivorans sp. nov., a new starch-hydrolysing lactic acid bacterium isolated during cassava sour starch fermentation. Int $J$ Syst Bacteriol 48, 1101-1109.

Swezey, J. L., Nakamura, L. K., Abbott, T. P. \& Peterson, R. E. (2000). Lactobacillus arizonensis sp. nov. isolated from jojoba meal. Int J Syst Evol Microbiol 50, 1803-1809.

Tanasupawat, S., Shida, O., Okada, S. \& Komagata, K. (2000). Lactobacillus acidipiscis $\mathrm{sp}$. nov. and Weissella thailandensis $\mathrm{sp}$. nov., isolated from fermented fish in Thailand. Int J Syst Evol Microbiol 50, 1479-1485.

Tynkkynen, S., Satokari, R., Saarela, M., Mattila-Sandholm, T. \& Saxelin, M. (1999). Comparison of ribotyping, randomly amplified polymorphic DNA analysis, and pulsed-field gel electrophoresis in typing of Lactobacillus rhamnosus and L. casei strains. Appl Environ Microbiol 65, 3908-3914.

Wayne, L. G. (1994). Action of the Judicial Commission on the International Commitee on Systematic Bacteriology on Requests for Opinions published between 1991 and 1992. Int J Syst Bacteriol 44, 177-178.

Yoon, J.-H., Kang, S.-S., Mheen, T.-I. \& 7 other authors (2000). Lactobacillus kimchii sp. nov., a new species from kimchi. Int $J$ Syst Evol Microbiol 50, 1789-1795.

Zhong, W., Millsap, K., Bialkowska-Hobrzanska, H. \& Reid, G. (1998). Differentiation of Lactobacillus species by molecular typing. Appl Environ Microbiol 64, 2418-2423. 